\title{
The Specificity of Environmental Influence: Socioeconomic Status Affects Early Vocabulary Development Via Maternal Speech
}

\author{
Erika Hoff
}

\begin{abstract}
The hypothesis was tested that children whose families differ in socioeconomic status (SES) differ in their rates of productive vocabulary development because they have different language-learning experiences. Naturalistic interaction between 33 high-SES and 30 mid-SES mothers and their 2-year-old children was recorded at 2 time points 10 weeks apart. Transcripts of these interactions provided the basis for estimating the growth in children's productive vocabularies between the first and second visits and properties of maternal speech at the first visit. The high-SES children grew more than the mid-SES children in the size of their productive vocabularies. Properties of maternal speech that differed as a function of SES fully accounted for this difference. Implications of these findings for mechanisms of environmental influence on child development are discussed.
\end{abstract}

Family socioeconomic status (SES) is a powerful predictor of many aspects of child development. An aim of current research is to identify the pathways by which SES exerts its well-established influence (DeGarmo, Forgatch, \& Martinez, 1999; Keating \& Hertzman, 1999; Linver, Brooks-Gunn, \& Kohen, 2002; National Research Council and Institute of Medicine, 2000). Because SES and child development are multifaceted variables and because many factors that influence child development covary with SES, the causal relations underlying SES effects on child development may be difficult to uncover (Hoff, Laursen, \& Tardif, 2002). The present study focused on one reliably observed relation between SES and child development and sought to identify the underlying mechanism.

The relation in focus is that between SES and early vocabulary development. It is well established that children from lower SES build their vocabularies at slower rates than children from higher SES (Arriaga, Fenson, Cronan, \& Pethick, 1998; Dollaghan et al., 1999; Feldman et al., 2000; Hart \& Risley, 1995; Hoff, in press; Morrisset, Barnard, Greenberg, Booth, \& Spieker, 1990; Rescorla, 1989; Rescorla \& Alley, 2001). This relation could be the result of several factors

Erika Hoff, Department of Psychology, Florida Atlantic University.

I am grateful to the anonymous reviewers for their comments and to Ryan Adams, Brett Laursen, and Todd Shackelford for discussion of the ideas in this manuscript. Data collection was supported by National Institute of Child Health and Human Development Grant HD20936.

Correspondence concerning this article should be addressed to Erika Hoff, Department of Psychology, Florida Atlantic University, 2912 College Avenue, Davie, FL 33314. Electronic mail may be sent to ehoff@fau.edu. including (a) biologically based differences in children's abilities, caused by genes or health; (b) global effects of differences in family functioning and home environments (Linver et al., 2002); and (c) specific effects of differences in language-learning experiences (Hoff \& Naigles, 2002; Hoff-Ginsberg, 1998).

Each of the candidate explanations of the SESchild language relation derives from a broader scope theory of how and to what extent the environment influences development in general and language acquisition in particular. One view is that development, in particular language development, unfolds following a genetic blueprint (e.g., Pinker, 2002). The alternative view, of course, is that the environment plays a substantial role. Pointing to the environment, however, does not explain how the environment exerts its influence. It could be that the effect of the environment is global. That is, supportive environments benefit all aspects of development and unsupportive environments impede them. The fact that the effects of SES are pervasive and cross developmental domains is consistent with this global effect model. On the other hand, a variety of evidence argues for the principle of environmental specificity, according to which different aspects of the environment influence different aspects of development (Wachs, 1991). For example, the aspects of maternal behavior that predict language development are different from the aspects of maternal behavior that predict play development (Lyytinen, Eklund, \& Lyytinen, 2003; Tamis-LeMonda \& Bornstein, 1994). Within language, the aspects of experience that influence the development of

(C) 2003 by the Society for Research in Child Development, Inc. All rights reserved. 0009-3920/2003/7405-0009 
communicative skill are different from the aspects of experience that influence the development of language knowledge (Bernicot \& Roux, 1998; HoffGinsberg, 1998; Wachs \& Chan, 1986).

The goal of this study was to pursue the principle of environmental specificity as an explanation of the relation between SES and language development. The hypothesis tested was that SES-related differences in children's vocabulary development can be explained as the result of SES-related differences in their language-learning experiences. For very young children whose mothers who do not work outside the home, their mothers are the primary source of their language-learning experience. The present study examined such a sample of children and tested the hypothesis that maternal speech mediates the relation between SES and child vocabulary development.

A large body of circumstantial evidence supports this mediation hypothesis. Mothers' talk to children differs as a function of SES (Hoff et al., 2002), and properties of mothers' talk to children account for individual differences in the rate of children's vocabulary development (Hoff \& Naigles, 2002; Huttenlocher, Haight, Bryk, Seltzer, \& Lyons, 1991; Naigles \& Hoff-Ginsberg, 1998). Higher SES mothers show more of the characteristics of maternal speech that are positively associated with language development than lower SES mothers (Hoff et al., 2002). Demonstrating that maternal speech mediates the SES-child vocabulary relation, however, requires evidence from a single sample that SES is related to both child language experience and child vocabulary growth and, furthermore, that relation of SES to child vocabulary growth can be accounted for in terms of child language experience.

The sample reported on in Hoff-Ginsberg (1998) and Hoff and Naigles (2002) provided the data required to test the mediation hypothesis. Previous analyses of this sample found SES-related differences in maternal speech and in child vocabulary growth (Hoff-Ginsberg, 1998) and relations between properties of maternal speech and children's vocabulary sizes (Hoff \& Naigles, 2002). What remains to be demonstrated is that the relation between maternal speech and child vocabulary explains the relation between SES and child vocabulary. The present study was designed to provide that demonstration. The previously reported effects of SES and input on child vocabulary were recalculated here using correlation and regression to provide measures of variance accounted for that mesh with the new analyses that test the mediation hypothesis.

\section{Method}

\section{Participants}

Sixty-three mothers and children were drawn from two socioeconomic strata. There were 33 highSES families in which both parents were college educated and, if employed, worked in professional or managerial positions. There were 30 mid-SES families in which both parents were high school educated but had no education beyond high school other than technical training and, if employed, worked in unskilled, semiskilled, or service positions. Thus, by design, SES was not a continuous variable in this study. Rather, the families who participated were drawn from two, nonoverlapping groups. In terms of maternal education, the mothers represented two levels: high school educated and college educated. Outside of extreme poverty, maternal education appears to be the component of SES most strongly related to parenting measures (Bornstein, Hahn, Suwalsky, \& Haynes, 2003; Hoff et al., 2002). All the mothers were native speakers of English, were the primary caretakers for their children, and were not employed outside the home more than $15 \mathrm{hr}$ per week. All the households were monolingual.

The high-SES group included 16 firstborns and 17 laterborns, including 9 secondborns, 6 thirdborns, and 2 fourthborns. The mid-SES group contained 17 firstborns and 13 laterborns, including 11 secondborns and 2 thirdborns. Thus, the mean birth order of the high-SES children was higher than mean birth order of the mid-SES children (1.8 and 1.5, respectively). The gender composition of each group was as follows: Among the 16 high-SES firstborns there were 7 girls and 9 boys; among the 17 mid-SES firstborns there were 9 girls and 8 boys; among the 17 high-SES laterborns there were 10 girls and 7 boys; among the 13 mid-SES laterborns there were 5 girls and 8 boys.

The children were all selected to be as comparable as possible in terms of their levels of language development. At the start of the study, all children were just beginning to combine words, but no more than $50 \%$ of any child's utterances were multiple word constructions. Age was not a selection criterion and ranged from 16 to 31 months. For the high-SES children, the mean age was 20.8 months $(S D=3.1)$ and mean length of utterances (MLU) was 1.26 $(S D=.12)$. For the mid-SES children, the mean age was 21.6 months $(S D=3.0)$ and MLU was 1.28 $(S D=.12)$. Neither the group difference in age or MLU approached significance, $p \mathrm{~s}>.4$. 


\section{Database}

The database consisted of transcripts of the conversations that occurred during videorecorded interactions between the mothers and their children. The conversations were recorded in the participants' homes as the mothers got their children dressed for the day, fed them breakfast, and played with an experimenter-provided set of toys. These interactions were recorded in the home twice 10 weeks apart. The measures of maternal speech are based on transcripts of the first visit (Time 1). The dressing, mealtime, and toy play interactions at Time 1 together averaged approximately $43 \mathrm{~min}$, including an average of $17 \mathrm{~min}$ of mealtime, $8 \mathrm{~min}$ of dressing, and $18 \mathrm{~min}$ of toy play. The mealtime interactions contributed $36 \%$ of maternal speech sample; dressing, 23\%; and toy play, $41 \%$. The transcripts were prepared first from audiotapes, which were copied from the videotaped recordings, and then were checked against the videotape and notes made by an observer during the taping sessions. The transcription was done by trained research assistants using the Systematic Analysis of Language Transcripts (SALT) software (Miller \& Chapman, 1995). The sample and procedures are more fully described in Hoff-Ginsberg $(1991,1998)$.

\section{Measures}

Maternal speech. The measures of maternal speech were designed to capture both linguistic properties of the input the children received and social properties of the interactions they experienced. As a measure of both sorts of properties, the total number of utterances produced was counted from the full transcripts, making no correction for differences in the durations of the interactions. Some mothers talked more than other mothers, and their interactions with their children lasted longer as a result. Variance in properties of children's language experience that results from differences in maternal volubility is a real part of the variance in children's experience, with demonstrated consequences for their language development (Hart \& Risley, 1995). It was therefore included in the current measures of children's input (see Hoff-Ginsberg, 1992a, 1992b, for discussion). Measures of the linguistic properties of input included the number of word tokens and the number of word types mothers produced, also counted from the full transcripts, and MLU, in morphemes. The types measure was a count of the number of different word roots mothers produced, counting book and books and run and running as instances of the same roots, for example. These measures were all calculated by SALT. As indexes of social properties of interaction, two subcategories of maternal utterances were also coded and counted: the number of utterances in episodes of joint attention and the number of topic-continuing replies to the child. Joint attention was defined following Tomasello and Farrar (1986) as periods lasting $3 \mathrm{~s}$ or more during which the mother and child were both focused on the same object or activity. This measure was calculated on the toy play interaction only because in the other settings both parties were not always in view of the camera at the same time. Topic-continuing replies were defined following Hoff-Ginsberg (1987) as utterances that immediately followed a child utterance and that referred to an entity or event that was referred to in the child's prior utterance. The correlation between two coders' estimates of time in joint attention on 6 independently coded videotapes was $r(4)=.98$, the interrater agreement rate for the code that included topiccontinuing replies was $87 \%$, with a kappa of .80 , based on codings of 220 utterances from two different transcripts.

Child vocabulary. Because the purpose of the measure of child vocabulary was to assess productive competence, it was considered important not to allow differences among the children in the amount of speech they produced to influence that measure. (This is in contrast to the measure of maternal speech that was designed to capture what children actually heard, not what their mothers could do.) For the children, therefore, equivalent-length speech samples were created by truncating the mealtime, dressing, and toy play transcripts so that each setting contributed in approximately equivalent proportions to the speech sample for each child but so that there were exactly 90 utterances in each speech sample; 90 was the number of utterances available in the smallest speech sample. The measure of productive vocabulary was then the number of word types in the 90-utterance speech sample.

\section{Data Analysis Plan}

Four conditions must be met to demonstrate mediation (Baron \& Kenny, 1986; Holmbeck, 1997): (a) the predictor variable (in this case, SES) must be significantly associated with the outcome (child vocabulary), (b) the predictor must be significantly associated with the hypothesized mediators (properties of maternal speech), (c) the hypothesized mediators must be significantly associated with the 
outcome, and (d) the strength of the association between the predictor and the outcome must be reduced by removing the variance attributable to the mediators. In the present study these associations were tested with correlations and multiple regression analyses. Structural equation modeling (SEM) also can be used to test for mediated effects, but the value of SEM lies primarily in its ability to use multiple indicators of latent variables, and SEM requires a large sample (Holmbeck, 1997). In the present study the predictor and outcome were single variables; the hypothesized mediators were a small, well-defined set; and the current sample size was not sufficient to support SEM.

\section{Results}

Descriptive statistics for the measure of child vocabulary at Times 1 and 2 are presented in Table 1 . There was no SES-related difference in the number of word types produced at Time $1(p>.4)$, and the difference between the number of word types produced at Time 1 and Time 2 was significant for both groups, for the high-SES children, $t(32)=6.18$, $p<.001$, and for the mid-SES children, $t(29)=5.69$, $p<.001$. Thus, the two groups of children started at equivalent levels at Time 1 and grew in vocabulary use from Time 1 to Time 2, setting the stage for the focal questions of whether the two groups of children grew at different rates and whether input explained why. Descriptive statistics for the measures of the hypothesized mediators in maternal speech are presented in Table 2.

The analyses of the relations among these variables and SES are presented in four sections as they address the conditions necessary to demonstrate mediation. In all analyses involving SES, the effect of birth order was statistically removed because there were more laterborns in the high-SES group than the mid-SES group and because previous analyses found birth order to be related to maternal speech and to child vocabulary size in this sample (HoffGinsberg, 1998). In all analyses predicting child vocabulary, the outcome measure was the children's vocabulary sizes at Time 2 , and the variance attributable to vocabulary size at Time 1 was removed. Time 1 variance was removed to avoid spurious correlations between maternal speech and child language at Time 2 that might result from both measures being related to child language at Time 1 (Newport, Gleitman, \& Gleitman, 1977). Because this is a conservative procedure for estimating input effects (Huttenlocher et al., 1991), it is also a conservative procedure for testing the current
Table 1

Means (and Standard Deviations) for the Child Vocabulary Measure at Time 1 and Time 2 for Mid-and High-SES Children

\begin{tabular}{llc}
\hline & \multicolumn{2}{c}{$\begin{array}{l}\text { Number of word types in 90 } \\
\text { utterances of children's } \\
\text { spontaneous speech }\end{array}$} \\
\cline { 2 - 3 } & Time 1 & Time 2 \\
\hline Mid SES & 35.33 & 45.53 \\
High SES & $(7.18)$ & $(9.46)$ \\
& 36.73 & 51.00 \\
& $(8.86)$ & $(15.19)$ \\
\hline
\end{tabular}

Note. SES $=$ socioeconomic status.

Table 2

Means (and Standard Deviations) for Properties of Maternal Speech at Time 1

\begin{tabular}{lcc}
\hline Maternal speech property & Mid SES & High SES \\
\hline Number of utterances & 522.37 & 697.36 \\
& $(195.85)$ & $(233.76)$ \\
Number of word tokens & 1570.40 & 2165.12 \\
& $(537.55)$ & $(832.96)$ \\
Mean length of utterance & 3.48 & 3.63 \\
& $(0.35)$ & $(0.49)$ \\
Number of word types & 269.00 & 324.18 \\
& $(58.21)$ & $(91.85)$ \\
Number of utterances in episodes of & 101.1 & 100.94 \\
joint attention & & \\
& $(60.87)$ & $(58.05)$ \\
Number of topic-continuing replies & 111.67 & 147.12 \\
& $(55.25)$ & $(55.51)$ \\
\hline
\end{tabular}

Note. SES = socioeconomic status.

hypothesis that input mediates the SES-child language relation. In principle, effects of child age on maternal speech and child language development could similarly result in spurious correlations, but in the present sample there were no significant correlations between child age and any measure of maternal speech.

\section{Relation of SES to Child Vocabulary}

Multiple regression with hierarchical analysis of variables (Cohen, Cohen, West, \& Aiken, 2003) was used to estimate the variance in child vocabulary at Time 2 that was attributable to SES, after the variance attributable to birth order and child vocabulary at Time 1 were removed. The results, presented in Table 3, show that birth order and Time 1 status accounted for $23 \%$ of the variance in child vocabulary at Time 2 and that SES accounted for an 
Table 3

Hierarchical Analysis Predicting the Variance in Child Vocabulary at Time 2 Uniquely Attributable to SES, Removing Effects of Birth Order and Time 1 Vocabulary $(N=63)$

\begin{tabular}{lrcc}
\hline Variable & $B$ & SE $B$ & $\beta$ \\
\hline Step 1 & & & \\
$\quad$ Birth order & -2.70 & 1.81 & .17 \\
$\quad$ Time 1 vocabulary & 0.68 & 0.18 & $.42^{* * * * *}$ \\
$R^{2}$ for Step 1 =.23 & & & \\
Step 2 & & & \\
$\quad$ Birth order & -3.43 & 1.81 & $-.22^{* *}$ \\
$\quad$ Time 1 vocabulary & 0.64 & 0.18 & $.40^{* * * *}$ \\
SES & -5.67 & 2.94 & $-.22^{*}$ \\
$\Delta R^{2}$ for Step 2 =.05 & & &
\end{tabular}

Note. SES $=$ socioeconomic status.

$* p<.05$, one-tailed. $* * * *<.001$, one-tailed.

additional, significant $5 \%$ of the variance. Thus, the first condition for demonstrating mediation was met: the predictor (SES) was significantly associated with the outcome (child vocabulary).

\section{Relation of SES to Maternal Speech Properties}

Partial correlations, holding birth order constant, assessed the relation of SES to the hypothesized mediating properties of maternal speech. The results, presented in Table 4, revealed that SES was related to five of the six tested properties of maternal speech. The high-SES mothers produced more utterances, more word tokens, and more word types; had higher MLUs; and produced more topiccontinuing replies to their children than did the mid-SES mothers. There was no SES-related difference in the number of utterances that were produced during episodes of joint attention. These correlations satisfied the second condition for demonstrating mediation: The predictor (SES) was significantly associated with hypothesized mediators (measures of maternal speech) of the predictor $\rightarrow$ outcome relation.

\section{Relation of SES-Related Maternal Speech Properties to Child Vocabulary}

The first analysis of the relations between the hypothesized mediating properties of maternal speech and the child vocabulary outcome at Time 2 used partial correlations to assess the predictive power of each speech property alone. Three properties of mothers' child-directed speech were positive predictors of child vocabulary at Time 2: number of word tokens, number of word types, and MLU. The
Table 4

Partial Correlations of SES to Hypothesized Mediators in Properties of Maternal Speech

\begin{tabular}{lc}
\hline Maternal speech properties & SES \\
\hline Number of utterances & $-.37^{* * *}$ \\
Number of word tokens & $-.39^{* * * *}$ \\
Mean length of utterance & $-.23^{*}$ \\
Number of word types & $-.36^{* *}$ \\
Number of utterances in episodes & .04 \\
$\quad$ of joint attention & $-.31^{* *}$ \\
Number of topic-continuing replies & \\
\hline Note. SES = socioeconomic status. Birth order is held constant. \\
$* p<.05$, one-tailed. $* * p<.01$, one-tailed. $* * * p<.001$, one-tailed.
\end{tabular}

Table 5

Partial Correlations of Hypothesized Mediators to Child Vocabulary

Word types in

Maternal speech properties

child speech

Number of utterances

.05

Number of word tokens

$.21 *$

Mean length of utterance

$.55^{* * * * *}$

Number of word types

Number of utterances in episodes

$.22 * *$

of joint attention

Number of topic-continuing replies

.18

Note. Outcome is measured at Time 2; partial correlation holds Time 1 value of the outcome measure constant.

$* p<.05$, one-tailed. $* * p<.01$, one-tailed. $* * * p<.001$, one-tailed.

results are presented in Table 5. These three properties of maternal speech were intercorrelated. The number of tokens and number of types were highly related, $r(61)=.89, p<.001$, and both were significantly related to MLU, $r(61)=.35, p<.001$ and $r(61)=.48, p<.001$, respectively. The number of word tokens was therefore dropped from the set of mediators, as it was essentially redundant with the number of types. (The question of the separate roles in vocabulary development of these two intercorrelated properties of maternal speech is discussed in Hoff and Naigles, 2002, and Huttenlocher et al., 1991. It is not addressable within this sample because of the high multicollinearity of the two measures.) A second analysis used multiple regression to assess the predictive power of number of word types and MLU together. That regression is presented in Table 6 and shows that only MLU emerged as a significant predictor, uniquely accounting for $22 \%$ of the variance in child vocabulary. This relation satisfies the third condition for demonstrating mediation: There is a mediator (measures of maternal speech) that is related to the outcome (child vocabulary). 
Table 6

Hierarchical Analysis Predicting the Variance in Child Vocabulary at Time 2 Uniquely Attributable to Maternal Speech, Removing Effects of Birth Order and Time 1 Vocabulary $(N=63)$

\begin{tabular}{lrrc}
\hline Variable & $B$ & SE $B$ & $\beta$ \\
\hline Step 1 & & & \\
$\quad$ Birth order & -2.70 & 1.81 & .17 \\
$\quad$ Time 1 vocabulary & 0.68 & 0.18 & $.42^{* * * *}$ \\
$R^{2}$ for Step 1 =.23 & & & \\
Step 2 & -1.02 & 1.60 & -.06 \\
$\quad$ Birth order & 0.48 & 017 & $.30^{* * *}$ \\
$\quad$ Time 1 vocabulary & 0.00 & 0.02 & -.02 \\
$\quad$ Word types in maternal speech & 15.42 & 3.51 & $.51^{* * * * *}$ \\
$\quad$ MLU of maternal speech & & & \\
$\Delta R^{2}$ for Step 2 =.22 & & & \\
\hline
\end{tabular}

Note. SES = socioeconomic status; MLU = mean length of utterances.

$* * p<.01$, one-tailed. $* * * * p<.001$, one-tailed.

\section{Relation of SES to Child Vocabulary Holding Maternal} Speech Properties Constant

The last statistical analysis tested the mediation hypothesis using multiple regression with hierarchical analysis of variables to estimate the variance in child vocabulary uniquely associated with SES, holding the hypothesized mediators constant. The results of that analysis are presented in Table 7. After the $23 \%$ of variance attributable to birth order and child vocabulary and Time 1 was removed, the hypothesized mediating properties of maternal speech accounted for an additional $22 \%$ of the variance in child outcome, leaving only a nonsignificant $1 \%$ of the variance in child vocabulary growth attributable to SES. Thus, the fourth and critical condition for demonstrating mediation was met: The strength of the association between the predictor and outcome was reduced by removing the variance attributable to the mediators. In fact, full mediation was demonstrated because the association between SES and child vocabulary was no longer significant once the variance attributable to maternal speech was removed.

\section{Discussion}

The goal of the present study was to identify the mechanism by which SES influences children's productive vocabulary development. The findings indicated that maternal speech was the mediating variable: The observed difference in growth in productive vocabulary between a group of children from high-SES families and a group of children from
Table 7

Hierarchical Analysis Assessing the Variance in Child Vocabulary at Time 2 Uniquely Attributable to SES, Removing Effects of Birth Order, Time 1 Vocabulary, and Maternal Speech $(N=63)$

\begin{tabular}{lrcc}
\hline Variable & $B$ & SE $B$ & $\beta$ \\
\hline Step 1 & & & \\
$\quad$ Birth order & -2.70 & 1.81 & -.17 \\
$\quad$ Time 1 vocabulary & 0.68 & 0.18 & $.42^{* * * *}$ \\
$R^{2}$ for Step 1 =.23 & & & \\
Step 2 & & & \\
$\quad$ Birth order & -1.04 & 1.60 & -.07 \\
$\quad$ Time 1 Vocabulary & 0.48 & 0.16 & $.30^{* * *}$ \\
$\quad$ MLU of maternal speech & 15.18 & 3.13 & $.50^{* * * *}$ \\
$\Delta R^{2}$ for Step 2=.22 & & & \\
Step 3 & & & \\
$\quad$ Birth order & -1.54 & 1.63 & -.10 \\
$\quad$ Time 1 vocabulary & 0.47 & 0.16 & $.29^{* * *}$ \\
$\quad$ MLU of maternal speech & 14.35 & 3.19 & $.47^{* * * *}$ \\
$\quad$ SES & -3.18 & 2.61 & -.12 \\
$\Delta R^{2}$ for Step 3 =.01 & & & \\
\hline Nete. SES socioeconomic status; & & & \\
\hline
\end{tabular}

Note. SES = socioeconomic status; MLU = mean length of utterances.

$* * *<<.01$, one-tailed. $* * * p<.001$, one-tailed.

mid-SES families was fully explained in terms of differences in their mothers' speech. Identification of the mediating variable is not a description of the mechanisms that underlie the effect of SES, but it provides a starting point for pursuing such a description.

\section{How Maternal Speech Mediates the SES-Child Language Relation}

The mechanism by which SES affects child language development via maternal speech must have two components: (a) the process by which SES affects maternal speech and (b) the process by which maternal speech affects language growth. With respect to the first process, data from the present sample suggest that SES-related differences in childdirected speech arise from more general SES-related differences in language use. The presently observed differences in the quantity, lexical richness, and sentence complexity of mothers' speech to their children were also found in the speech these mothers addressed to a researcher in an open-ended interview about childrearing goals (Hoff-Ginsberg, 1991). The present sample of mothers showed no differences in their childrearing beliefs or goals, but in the population more broadly these, too, may be sources of SES-related differences in child-directed speech. Parents from different social strata may hold 
different beliefs about the value and appropriateness of talking to children or about the desirability of having a talkative child, and they may behave differently as a result (Heath, 1983; Snow, de Blauw, \& Van Roosmalen, 1979). SES may also be associated with differences in the time available for leisurely parent-child interaction and in the magnitude of other stresses on parents, and these shape parents' interactions with their children (Hoff et al., 2002; Snow, Dubber, \& de Blauw, 1982).

The process by which maternal speech affects language growth suggested by the present findings is by providing data to the child's word-learning mechanisms. Children who heard longer utterances built productive vocabularies at faster rates than children who heard shorter utterances. There may be several reasons for this. First, the variance in utterance length includes variance in the number of word types. That is, the mothers who spoke in longer utterances also used a richer vocabulary, and the more different words children hear, the more different words they may learn. The finding that word types contributed no predictive power beyond the predictive power of MLU does not contradict this conclusion. Because longer utterances typically both include more content words and are of greater grammatical complexity than shorter utterances (Rollins, Snow, \& Willett, 1996), the relation between word types and MLU is, to a degree, the relation between a part of a measure and the whole. The variance in the part may have real effects, but it has no unique effect beyond the variance in the whole that includes it. Second, longer utterances may provide more information about word meaning because discussion of word meaning, which many mothers do (Gelman, Coley, Rosengren, Hartman, \& Pappas, 1998), requires longer utterances than does merely providing labels. Third, longer utterances provide richer and potentially more varied syntactic frames surrounding words, and syntax has been demonstrated to be a source of information regarding word meaning (Naigles \& Hoff-Ginsberg, 1998). Thus, the present data paint a picture in which the habitual style of language use among collegeeducated mothers influences the way they talk to their children, which in turn affects the rate at which their children build their productive vocabularies.

The present findings do not provide an exhaustive account of the properties of children's languagelearning environments that affect vocabulary development, nor does the variance accounted for by the measures in the present study indicate the full influence of environmental factors on language development. The present study looked only at maternal speech in everyday interactions and only at some measures of speech in that context. The time children spend in other contexts, such as book reading, and other properties of maternal vocabulary use, such as use of rare vocabulary, may also be relevant to vocabulary development (Hoff, 2003; Weizman \& Snow, 2001). The present study examined only a brief period of lexical development; other factors may be relevant during other periods (see Hoff \& Naigles, 2002, for a discussion). The present study did not sample the full range of SES in population. The lower group was not a low-SES group. The full range of SES no doubt includes a larger range of language-learning environments and associated differences in language development than captured in the present study.

Additionally, the present study underestimated the role of input because removing the variance attributable to the child at Time 1 has other effects besides the sought-for effect of eliminating spurious correlations due to effects of the child on maternal speech. It also removes variance in maternal speech that affected the child's language up to Time 1 , and it removes variance in maternal speech that is relevant to language development but that is elicited by properties of the child's language use (e.g., see HoffGinsberg, 1994). This concern is consistent with arguments from the study of other domains of development that whenever the experiences relevant to development involve interactions with others, children's own behavior is likely to influence their experiences, and thus procedures that exclude such experiences will overlook real environmental effects (Rutter, Pickles, Murray, \& Eaves, 2001). ${ }^{1}$

\footnotetext{
${ }^{1}$ To pursue this concern in the present data, the predictive relations between properties of maternal speech that differed as a function of SES and child vocabulary at Time 2 were reanalyzed without removing the variance attributable to the child at Time 1. One additional measure of maternal input predicted child vocabulary at Time 2: the number of topic-continuing replies to the child $(r=.27, p<.05)$. When this additional variable was included as a measure of maternal speech and when variance attributable to child level at Time 1 was not removed, the variance in child vocabulary at Time 2 accounted for by input increased from the $22 \%$ shown in Table 6 to $34 \%$. The test of whether maternal speech mediates the SES effect was also performed again without removing the variance attributable to the child at Time 1 and including topic-continuing replies among maternal speech measures. The result was that the variance attributable to SES after removing effects of maternal speech was a nonsignificant $1 \%$. Thus, not partialling out the effects of the child at Time 1 from the present analyses increased the variance in child productive vocabulary attributable to maternal speech and left unaffected the finding that maternal speech mediates the SES-child productive vocabulary relation.
} 
Another caveat concerning the present findings is that they leave ambiguous the nature of the effect of maternal speech on language development because the outcome measure employed was ambiguous. The relative sizes of children's productive vocabularies was assessed by counting the number of different words the children produced in samples of spontaneous speech. Spontaneous speech measures have the advantage that they avoid bias, which is possible in a test of vocabulary knowledge that uses a predetermined set of words. However, the words children use in talking reflect both the words children have available to use and the process by which they choose which words to use; it is not a pure measure of vocabulary knowledge. Ease of lexical access and style of language use also influence the vocabulary used in spontaneous speech, and both of these factors may be influenced by language experience. The frequency with which children hear words may influence the ease with which they retrieve them as they speak, and children learn not only language but also a style of language use from their linguistic experiences. In the same vein, findings from studies of 4- and 5-year-olds suggest there are more likely to be SES-related differences in children's productive vocabularies than in their comprehension vocabularies (Hoff, in press; Snow, 1999).

The point of this caution is not to argue away the SES-related difference we initially sought to explain; rather, it is to admit that we do not fully understand the degree to which the difference between mid-SES and high-SES children in the size of the vocabularies they use reflects differences in language knowledge or differences in lexical access and style of language use. The present findings should be taken as evidence that one reason children from different social strata use different-sized vocabularies is that they have different language experiences. It is a task for future research to untangle the differences in children's vocabulary use that arise from knowledge from those that reflect style.

How the Environment Influences Development: Support for the Environmental Specificity Hypothesis

The present evidence for the role of maternal speech in explaining the SES-related difference in children's productive vocabularies reduces the need for alternative explanations. There is no need to posit biological-based SES-related differences in children's word-learning abilities, whether based in domain- general or language-specific endowment. The present findings suggest, to the contrary, that the frequently observed SES-related difference in IQ (Scarr, 1981) may be a result, rather than a cause, of SES-related differences in vocabulary, which in turn have their roots in differences in experience. Vocabulary is a large component of most IQ tests, but vocabulary differences indicate ability differences only on the assumption of equal opportunity to acquire a vocabulary. The present findings demonstrate that the aspects of experience that support vocabulary acquisition are not equally available to children across socioeconomic strata. A further argument against a genetic explanation of the presently observed SES effect is that birth order also was related to maternal MLU and to vocabulary growth (Hoff-Ginsberg, 1998).

The present findings not only locate the source of SES-related differences in children's language development in their environments, they also argue for the principle of environmental specificity rather a model of global environmental influence. Not every measure that differed as a function of SES predicted child vocabulary; thus, it is not that any experiential correlate of SES predicts any developmental correlate of SES. Rather, the picture of environmental influence and of SES effects that the present findings suggest is one in which vocabulary development depends on particular properties of language experience. Variability in these properties creates variability in the rate of children's vocabulary development regardless of SES. To the extent that the relevant features of experience vary as a function of SES, so too will vocabulary development vary as a function of SES. This result dovetails with findings from 5- to 6-year-olds that syntactic properties of the speech they hear accounts for SES-related differences in their syntactic knowledge (Huttenlocher, Vasilyeva, Cymerman, \& Levine, 2002). Both these findings are consistent with the principle of environmental specificity, according to which different aspects of development have unique environmental predictors (Wachs \& Chan, 1986), and they further extend that principle to the explanation of the effects of broad, distal variables such as SES, suggesting that SES affects child development through multiple, specific pathways - each path reflecting the specific proximal processes (Bronfenbrenner \& Morris, 1998) by which environmental factors exert their influence. An important implication of the specificity principle is that specific remediation should be effective. Thus, enriching children's language experience should have beneficial effects on the vocabulary development of lower SES children, even when other SES- 
related differences in children's environments remain unaddressed.

The conclusion that the principle of environmental specificity is supported should be tempered, however, by a consideration of the nature of the current sample. The participants represented only a portion of the range of socioeconomic strata - a portion at the high end. None of the children in this study lived in poverty. This limited range provides an advantage in that it allows demonstrating that there are SES-related differences in maternal speech with consequences for child language development, even where other factors that typically covary with SES do not apply. On the other hand, because this sample does not represent the full range of social strata, the variance in this sample attributable to SES and the degree to which the effect of SES is mediated by maternal speech may not be representative of those relations in the population. In the present sample only $5 \%$ of the variance in children's vocabularies was attributable to SES, but in the population as a whole it is probably greater. Furthermore, it is possible that maternal speech is a smaller part of the explanation of SES effects where there are large differences in health, nutrition, and overall stimulation that may have pervasive effects on development. It is a topic for future research to investigate the degree to which the environmental specificity principle applies across the full SES gradient.

In conclusion, common belief and scientific evidence are in agreement that children from more advantaged homes have more advanced language skills than children of the same age from less advantaged homes. The evidence presented here suggests that one source of the SES-related difference in 2-year-old children's vocabulary use is SESrelated differences in the speech children hear. These findings are consistent with the view that specific aspects of language development depend on specific properties of language experience and thus with the principle of environmental specificity. This identification of one pathway through which SES affects one aspect of child development is consistent with the broader view that the pervasive effects of SES on child development comprise multiple specific relations between aspects of children's experience that vary as a function of SES and the developmental outcomes that these experiences affect.

\section{References}

Arriaga, R. J., Fenson, L., Cronan, T., \& Pethick, S. J. (1998). Scores on the MacArthur Communicative Development
Inventory of children from low- and middle-income families. Applied Psycholinguistics, 19, 209-223.

Baron, R. M., \& Kenny, D. A. (1986). The moderatormediator variable distinction in social psychological research: Conceptual, strategic, and statistical considerations. Journal of Personality and Social Psychology, 51, 1173-1182.

Bernicot, J., \& Roux, M. (1998). La structure et l'usage des enonces: Comparison d'enfants uniques et d'enfants second nes [The structure and function of sentences: Comparison of only children and second born children]. In J. Bernicot, H. Marcos, C. Day, M. Guidette, J. RabainJamain, V. Laval, \& G. Babelot (Eds.), De l'usage des gestes et des mots chez les enfants [On the function of gesture and words in the infant] (pp. 157-178). Paris: Armand Colin.

Bornstein, M. H., Hahn, C.-S., Suwalsky, J. T. D., \& Haynes, O. M. (2003). Socioeconomic status, parenting, and child development: The Hollingshead four-factor index of social status and the socioeconomic index of occupations. In M. H. Bornstein \& R. H. Bradley (Eds.), Socioeconomic status, parenting, and child development (pp. 29-82). Mahwah, NJ: Erlbaum.

Bronfenbrenner, U., \& Morris, P. A. (1998). The ecology of developmental processes. In W. Damon(Series Ed.) \& R. M. Lerner (Vol. Ed.), Handbook of child psychology, Vol. 1: Theoretical models of human development (5th ed., pp. 993 1028). New York: Wiley.

Cohen, J., Cohen, P., West, S. G., \& Aiken, L. S. (2003). Applied multiple regression/correlation analysis for the behavioral sciences (3rd ed.), Mahwah, NJ: Erlbaum.

DeGarmo, D. S., Forgatch, M. S., \& Martinez, C. R. Jr. (1999). Parenting of divorced mothers as a link between social status and boys' academic outcomes: Unpacking the effects of socioeconomic status. Child Development, 70, 1231-1245.

Dollaghan, C. A., Campbell, T. F., Paradise, J. L., Feldman, H. M., Janosky, J. E., Pitcairn, D. N., et al. (1999). Maternal education and measures of early speech and language. Journal of Speech, Language, and Hearing Research, 42, 1432-1443.

Feldman, H. M., Dollaghan, C. A., Campbell, T. F., KursLasky, M., Janosky, J. E., \& Paradise, J. L. (2000). Measurement properties of the MacArthur Communicative Development Inventory at ages one and two years. Child Development, 71, 310-322.

Gelman, S. A., Coley, J. D., Rosengren, K. S., Hartman, E., \& Pappas, A. (1998). Beyond labeling: The role of maternal input in the acquisition of richly structured categories. Monographs of the Society for Research in Child Development, 63, (1 Serial No. 253).

Hart, B., \& Risley, T. (1995). Meaningful differences in the everyday experience of young American children. Baltimore: Brookes.

Heath, S. B. (1983). Ways with words: Language, life, and work in communities and classrooms. Cambridge, England: Cambridge University Press. 
Hoff, E. (2003). Causes and consequences of SES-related differences in parent-to-child speech. In M. H. Bornstein (Ed.), Socioeconomic status, parenting, and child development (pp. 147-160). Mahwah, NJ: Erlbaum.

Hoff, E. (in press). Poverty effects. In R. D. Kent (Ed.), MIT encyclopedia of communication disorders. Cambridge, MA: MIT Press.

Hoff, E., Laursen, B., \& Tardif, T. (2002). Socioeconomic status and parenting. In M. H. Bornstein (Ed.), Handbook of parenting (2nd ed., pp. 231-252). Mahwah, NJ: Erlbaum.

Hoff, E., \& Naigles, L. (2002). How children use input in acquiring a lexicon. Child Development, 73, 418-433.

Hoff-Ginsberg, E. (1987). Topic relations in mother-child conversation. First Language, 7, 145-158.

Hoff-Ginsberg, E. (1991). Mother-child conversation in different social classes and communicative settings. Child Development, 62, 782-796.

Hoff-Ginsberg, E. (1992a). How should frequency in input be measured? First Language, 12, 233-244.

Hoff-Ginsberg, E. (1992b). Methodological and social concerns in the study of children's language-learning environments: A reply to Pine. First Language, 12, 251-254.

Hoff-Ginsberg, E. (1994). Influences of mother and child on maternal talkativeness. Discourse Processes, 18, 105-117.

Hoff-Ginsberg, E. (1998). The relation of birth order and socioeconomic status to children's language experience and language development. Applied Psycholinguistics, 19, 603-629.

Holmbeck, G. N. (1997). Toward terminological, conceptual, and statistical clarity in the study of mediators and moderators: Examples from the child-clinical and pediatric psychology literatures. Journal of Consulting and Clinical Psychology, 65, 599-610.

Huttenlocher, J., Haight, W., Bryk, A., Seltzer, M., \& Lyons, T. (1991). Early vocabulary growth: Relation to language input and gender. Developmental Psychology, $27,236-248$.

Huttenlocher, J., Vasilyeva, M., Cymerman, E., \& Levine, S. (2002). Language input at home and at school: Relation to child syntax. Cognitive Psychology, 45, 337-374.

Keating, D. P., \& Hertzman, C. (1999). Developmental health and the wealth of nations. New York: Guildford.

Linver, M. R., Brooks-Gunn, J., \& Kohen, D. E. (2002). Family processes and pathways from income to young children's development. Developmental Psychology, 38, 719-734.

Lyytinen, P., Eklund, K., \& Lyytinen, H. (2003). The play and language behavior of mothers with and without dyslexia and its association to their toddlers' language development. Journal of Learning Disabilities, $36,74-86$.

Miller, J. F., \& Chapman, R. S. (1995). SALT: Systematic analysis of language transcripts. Madison: University of Wisconsin, Language Analysis Laboratory.

Morrisset, D., Barnard, K., Greenberg, M., Booth, C., \& Spieker, S. (1990). Environmental influences on early language development: The context of social risk Development and Psychopathology, 2, 127-149.

Naigles, L. R., \& Hoff-Ginsberg, E. (1998). Why are some verbs learned before other verbs? Effects of input frequency and stucture on children's early verb use. Journal of Child Language, 25, 95-120.

National Research Council and Institute of Medicine (2000). From neurons to neighborhoods: The science of early childhood development. Washington, DC: National Academy Press.

Newport, E. L., Gleitman, H., \& Gleitman, L. R. (1977). Mother I'd rather do it myself: Some effects and noneffects of maternal speech style. In C. Snow \& C. Ferguson (Eds.), Talking to children: Language input and acquisition (pp. 109-149). New York: Cambridge University Press.

Pinker, S. (2002). The blank slate. New York: Viking.

Rescorla, L. (1989). The Language Development Survey: A screening tool for delayed language in toddlers. Journal of Speech and Hearing Disorders, 54, 587-599.

Rescorla, L., \& Alley, A. (2001). Validation of the Language Development Survey (LDS): A parent report tool for identifying language delay in toddlers. Journal of Speech, Language, and Hearing Research, 44, 434-445.

Rollins, P. R., Snow, C. E., \& Willett, J. B. (1996). Predictors of MLU: Semantic and morphological development. First Language, 47, 243-259.

Rutter, M., Pickles, A., Murray, R., \& Eaves, L. (2001). Testing hypotheses on specific environmental causal effects on behavior. Psychological Bulletin, 127, 291-324.

Scarr, S. (1981). Race, social class, and individual differences in I.Q. Hillsdale, NJ: Erlbaum.

Snow, C. E. (1999). Social perspectives on the emergence of language. In B. MacWhinney (Ed.), The emergence of language (pp. 257-276). Mahwah, NJ: Erlbaum.

Snow, C. E., de Blauw, A., \& Van Roosmalen, G. (1979). Talking and playing with babies: The role of ideologies of child-rearing. In M. Bullowa (Ed.), Before speech: The beginning of interpersonal communication (pp. 269288). Cambridge, England: Cambridge University Press.

Snow, C. E., Dubber, C., \& De Blauw, A. (1982). Routines in mother-child interaction. In L. Feagans \& D. C. Farran (Eds.), The language of children reared in poverty (pp. 5372). New York: Academic Press.

Tamis-LeMonda, C. S., \& Bornstein, M. H. (1994). Specificity in mother-toddler language-play relations across the second year. Developmental Psychology, 30, 283-292.

Tomasello, M., \& Farrar, M. J. (1986). Joint attention and early language. Child Development, 57, 1454-1463.

Wachs, T. D. (1991). Environmental considerations in studies with nonextreme groups. In T. D. Wachs \& R. Plomin (Eds.), Conceptualization and measurement of 
organism-environment interaction (pp. 44-67). Washington, DC: American Psychological Association.

Wachs, T. D., \& Chan, A. (1986). Specificity of environmental action, as seen in environmental correlates of infants' communication performance. Child Development, $57,1464-1474$.
Weizman, Z. O., \& Snow, C. E. (2001). Lexical input as related to children's vocabulary acquisition: Effects of sophisticated exposure and support for meaning. Developmental Psychology, 37, 265-279. 